\title{
Use of the ReCIVA device in breath sampling of patients with acute breathlessness: a feasibility study
}

\author{
Karl A. Holden (10 ${ }^{1,5}$, Wadah Ibrahim ${ }^{1,5}$, Dahlia Salman², Rebecca Cordell ${ }^{3}$ \\ Teresa McNally ${ }^{1}$, Bharti Patel ${ }^{1}$, Rachael Phillips ${ }^{4}$, Caroline Beardsmore ${ }^{1}$, \\ Michael Wilde ${ }^{3}$, Luke Bryant ${ }^{3}$, Amisha Singapuri $^{1}$, Paul Monks $^{3}$, \\ Chris Brightling ${ }^{1}$, Neil Greening ${ }^{1}$, Paul Thomas ${ }^{1}$, Salman Siddiqui ${ }^{1,5}$ and \\ Erol A. Gaillard ${ }^{1,5}$
}

Affiliations: ${ }^{1}$ NIHR Leicester Biomedical Research Centre (Respiratory Theme), Glenfield Hospital, Leicester, UK. ${ }^{2}$ Loughborough University, Loughborough, UK. ${ }^{3}$ Dept of Chemistry, University of Leicester, Leicester, UK. ${ }^{4}$ NIHR Leicester Clinical Research Facility, Leicester Royal Infirmary, Leicester, UK. ${ }^{5}$ These authors contributed equally.

Correspondence: Erol A. Gaillard, University of Leicester, Department of Respiratory Sciences and NIHR Leicester Biomedical Research Centre (Respiratory Theme), Leicester, UK. E-mail: eag15aleicester.ac.uk

\section{ABSTRACT}

Introduction: Investigating acute multifactorial undifferentiated breathlessness and understanding the driving inflammatory processes can be technically challenging in both adults and children. Being able to validate noninvasive methods such as breath analysis would be a huge clinical advance. The ReCIVA ${ }^{\circ}$ device allows breath samples to be collected directly onto sorbent tubes at the bedside for analysis of exhaled volatile organic compounds (eVOCs). We aimed to assess the feasibility of using this device in acutely breathless patients.

Methods: Adults hospitalised with acute breathlessness and children aged 5-16 years with acute asthma or chronic stable asthma, as well as healthy adult and child volunteers, were recruited. Breath samples were collected onto sorbent tubes using the ReCIVA ${ }^{\star}$ device and sent for analysis by means of two-dimensional gas chromatography-mass spectrometry (GCxGC-MS). The NASA Task Load Index (NASA-TLX) was used to assess the perceived task workload of undertaking sampling from the patient's perspective.

Results: Data were available for 65 adults and 61 children recruited. In total, $98.4 \%$ of adults and $75.4 \%$ of children were able to provide the full target breath sample using the ReCIVA ${ }^{\bullet}$ device. NASA-TLX measurements were available in the adult population with mean values of 3.37 for effort, 2.34 for frustration, 3.8 for mental demand, 2.8 for performance, 3.9 for physical demand and 2.8 for temporal demand.

Discussion: This feasibility study demonstrates it is possible and acceptable to collect breath samples from both adults and children at the bedside for breathomics analysis using the ReCIVA ${ }^{\oplus}$ device.

@ERSpublications

It is feasible to collect breath samples for breath analysis at the bedside using the ReCIVA device in acutely breathless adults and children https://bit.ly/2ZTonWo

Cite this article as: Holden KA, Ibrahim W, Salman D, et al. Use of the ReCIVA device in breath sampling of patients with acute breathlessness: a feasibility study. ERJ Open Res 2020; 6: 00119-2020 [https://doi.org/10.1183/23120541.00119-2020]. 


\section{INTRODUCTION}

Breathlessness is a highly prevalent symptom in patients with cardiorespiratory compromise; it is invariably present at all stages of severity and is widely associated with adverse outcomes and poor quality of life [1]. Managing breathlessness has long been recognised as an important treatment goal in cardiorespiratory illnesses [2] and early recognition has been shown to improve outcomes [3]. Diagnostic evaluation of acute breathlessness is heavily reliant on clinical assessment and blood-based biomarkers, which have poor discriminatory power in patients with undifferentiated breathlessness and multifactorial presentations [4]. There remains an unmet need for the development of sensitive and specific noninvasive biomarkers that are native to the lung and can accurately diagnose undifferentiated cardiorespiratory breathlessness.

Airway inflammation plays an important role in many pathological processes in the lung, of which asthma is the commonest [5]. The associated oxidative stress and lipid peroxidation result in the conversion of polyunsaturated fatty acids into volatile organic compounds (VOCs) that can be detected in breath [6] VOCs are increasingly studied, with promising results, in diagnosing and monitoring cardiorespiratory illnesses [7-10]. Furthermore, there is evidence of proof-of-concept in being able to detect asthma in children [11]. Being able to apply this emerging area of research clinically would result in significant advances with potentially important clinical applications.

Exhaled breath VOC analysis has been favoured as it is noninvasive and requires minimal patient cooperation. This is particularly useful for investigating breathless patients attending when they are acutely unwell and those at both ends of the age spectrum.

Breath collection and analysis can be performed directly through online technologies, i.e. proton transfer reaction mass spectrometry (PTR-MS), compact mass spectrometry and ion mobility spectrometer or indirectly using offline technologies, e.g. gas chromatography-mass spectrometry (GC-MS), where breath is collected into various receptacles for analysis at a later stage. GC-MS analyses VOCs via initial chromatographic separation, followed by ionisation/fragmentation and mass separation, resulting in the generation of unique mass spectrometric fingerprints. Moreover, offline technologies allow decoupling of the breath sampling from the breath sensor and analysis platforms, allowing patients that are unable to mobilise to a real-time breath sampling device to be sampled at their bedside $[12,13]$. For these reasons, offline technologies have been widely adopted and are considered the gold standard technique for breath analysis in VOC discovery.

Numerous breath biomarker discovery studies have employed offline technologies, with a need for suitable breath collection receptacles, of which collection bags have been the most popular [14-17]. Although widely accepted, collection bags are not without considerable drawbacks that warrant further investigation. STEEGHS et al. [18] tested the suitability of black layered Tedlar ${ }^{\circledR}$ bags for breath sampling and identified
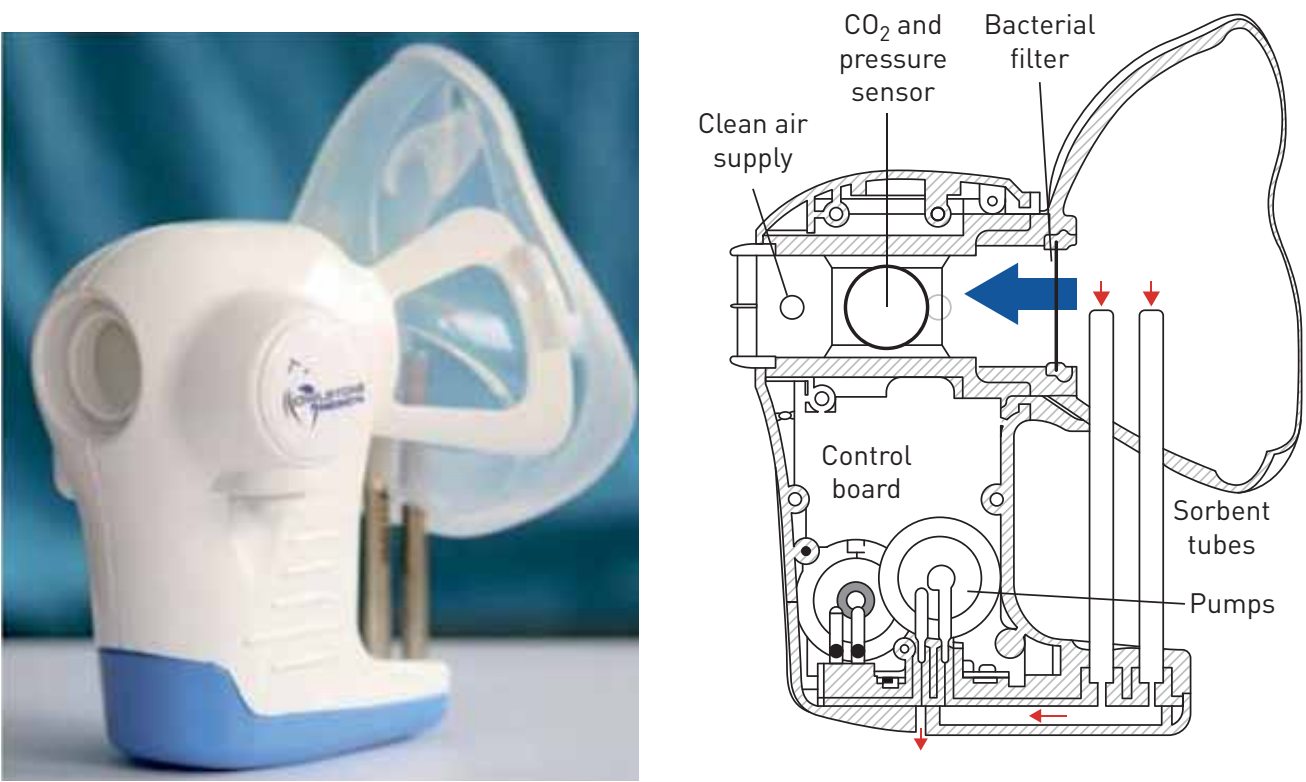

FIGURE 1 Owlstone CE marked breath sampler comprised of face mask, sorbent tubes, pumps and pressure sensors (adapted with permission from Owlstone Medical Ltd, Cambridge, UK). 
two abundant compounds that can contaminate the bag contents. Additionally, a considerable and reproducible compound loss was detected during bag filling. BEAUchamp et al. [19] carried out a comprehensive review on the use of Tedlar bags in breath-gas sampling and analysis and concluded that without appropriate sampling and handling techniques, problems like exponential compound decay and background emissions from bag material can interfere with accurate compound identification.

In an attempt to address these impediments, various direct breath collection devices have emerged over the last few years [20-22]. The ReCIVA ${ }^{\circ}$ breath sampler (Owlstone Medical, Cambridge, UK) is a handheld portable device, designed to collect breath samples directly from participants onto sorbent tubes (figure 1) [13]. This portable device means that breath sampling can theoretically take place at the patient's bedside, which is beneficial when investigating acutely breathless or unwell patients as they do not have to be removed from the clinical environment in which they are being treated. The ReCIVA ${ }^{\circ}$ device has been used as part of the EMBER acute study (East Midlands Breathomics Pathology Node, one of the six MRC and EPSRC supported molecular pathology nodes, hosted at the University of Leicester with partnerships with the University Hospitals of Leicester, NHS Trust, Loughborough University and industry) to collect samples of breath from adults and children presenting with acute breathlessness [12].

Our principal aim was to ascertain the feasibility and tolerability of exhaled breath sample collection from acutely breathless adults and children attending our hospital, using the ReCIVA ${ }^{\star}$ breath sampling device.

\section{Design and methods \\ Participants}

Adult patients with self-reported acute breathlessness, either requiring hospital admission or a change in baseline treatment, in addition to healthy volunteers, were recruited for the study. Informed consent was obtained from all participants following a clinical review by a senior decision-maker within $24 \mathrm{~h}$ of acute admission.

Children aged 5 to 16 years with acute asthma or with stable, chronic asthma attending either the Children's Emergency Department, Children's Assessment Unit or Children's Outpatients Department at Leicester Royal Infirmary (UK) were recruited. Age-matched children with no history of cardiorespiratory illnesses were also recruited as control participants.

For the paediatric cohort, parents provided informed written consent, and where possible, children signed age-appropriate assent forms. The study protocol was approved by the National Research Ethics Committee East Midlands (UK) (REC number: 16/LO/1747, IRAS: 198921). Further information on study protocol, design and methodology can be found elsewhere [12, 23].

\section{Breath sample collection and processing}

Adult patients had a senior physician diagnosis of either 1) acute asthma exacerbation, 2) acute COPD exacerbation, 3) acute decompensated heart failure, or 4) community-acquired pneumonia. Subject characteristics are shown in table 1 . All patients were recruited within $24 \mathrm{~h}$ of admission. Using the ReCIVA $^{\infty}$ device, $1 \mathrm{~L}$ of alveolar breath was collected onto thermal tubes along with room air and air supply samples. Collected samples were dispatched within $72 \mathrm{~h}$ to the University of Leicester and Loughborough University for GC-MS and GCxGC-MS analysis, respectively $[12,24]$. In an attempt to minimise background variation, sample collection was completed, when possible, in the same treatment room attached to the admissions ward. Unwell patients and those requiring supplemental oxygen had their samples collected by their bedside. The breath collection method has been previously described in detail [12]. Amount and time of oxygen administered to unwell patients were recorded and will be used in the data modelling and translational analysis.

Accompanied by their parents or guardians, children were tested in a treatment room attached to the emergency department. Children with acute asthma were tested when they no longer required supplemental oxygen and were deemed clinically well by their treating medical team.

During the sampling procedure, both adult and paediatric patients were coached on how the sampling process would work. Sat in an upright position, they were instructed to breathe normally via their mouth through the ReCIVA mask that was placed on their face. They were instructed not to talk but could communicate with their hands if they wished to stop the procedure. Children were distracted with age-appropriate books or games such as applications on a tablet device and were continually encouraged throughout.

\section{Breath sampling device}

The ReCIVA ${ }^{\oplus}$ device (figure 1) consists of a handheld unit to which a disposable silicone-based face mask is attached. During sampling, the device is connected to an air supply which delivers VOC-free air at 


\section{TABLE 1 Demographic details and details about ReCIVA $@$ breath samples collected in adults}

\begin{tabular}{|c|c|c|c|c|c|}
\hline & Acute asthma or COPD" & Acute heart failure & Pneumonia & Control & p-value \\
\hline Subjects $n$ & 22 & 14 & 15 & 14 & \\
\hline Age years & $69(19)$ & $72(14)$ & 59 (31) & $63.5(9)$ & $0.055^{\text {I }}$ \\
\hline Weight kg & $77(31)$ & $88.2(41)$ & 75 (28) & $77.7(30)$ & $0.489^{\pi}$ \\
\hline Males & 15 (68.2) & $9(64.3)$ & $7(46.7)$ & $6(42.9)$ & $0.359^{+}$ \\
\hline Able to collect $100 \%$ of the target sample & $21(95.5)$ & $14(100)$ & 15 (100) & $14(100)$ & $0.576^{+}$ \\
\hline
\end{tabular}

$>30 \mathrm{~L} \cdot \mathrm{min}^{-1}$. Up to four sorbent tubes are held within the device for the collection of breath. Within the handheld unit there are pressure sensors which allow contemporaneous measurement of the participant's respiration rate and their breath profile, along with the ability to gate the collection of samples to a particular breath phase. The ReCIVA device is coupled to software which allows the researcher to monitor the progress of the sample collection and respond to prompts from the software such as advising the patient to take slower or deeper breaths. The pumps within the device, when turned on, draw exhaled breath into the sorbent tubes, which results in the breath samples being trapped and also allows for pre-concentration of VOCs.

The device was programmed to collect $1 \mathrm{~L}$ of exhaled breath from the lower airways based on predefined breath sections, as programmed in the software, at a flow rate of $250 \mathrm{~mL} \mathrm{~min}{ }^{-1}$; these parameters were checked rigorously against a set of QA/QC criteria to ensure data consistency. The maximum time for sampling was $15 \mathrm{~min}$, however, most patients could achieve a $100 \%$ breath sample collection in under this time (tables 1 and 2). The ReCIVA ${ }^{\star}$ device was connected, via a laptop, to a locally developed informatics toolkit (LabPipe) to support sample/data collection from multiple sites for different analytical equipment [25]. The toolkit also includes data integration, user notifications and data warehouse linkage allowing for real-time error notifications.

\section{Room air and air supply sample collection}

A room air sample was also collected at the time of breath sampling. This involved attaching a sorbent tube (Tenax/TA with Carbograph 1TD, Markes International Ltd, Llantrisant, UK), the same sorbent tube as used for breath samples, to the inlet of a handheld air sampling pump (Escort ${ }^{\oplus}$ Elf, Sigma Aldrich, Dorset, UK). The pump was set to draw room air through the sorbent tube at $500 \mathrm{~mL} \mathrm{~min}{ }^{-1}$ for $2 \mathrm{~min}$.

An air supply sample was collected at least once a day. A stainless steel T-piece was connected to the end of the air supply tubing to allow the excess air flow to vent while a sorbent tube (the same sorbent tube as used for breath samples) was attached to the T-piece with the handheld pump connected to the other end of the tube. The room air and air supply samples were stored, prepared and analysed using the same analytical procedure as the breath samples.

\begin{tabular}{|c|c|c|c|c|}
\hline & Acute asthma & Stable asthma & Control & p-value \\
\hline Subjects $\mathbf{n}$ & 29 & 23 & 9 & \\
\hline Age years & $10.5(6)$ & $12(4)$ & $11.5(8)$ & $0.057^{\#}$ \\
\hline Height $\mathrm{cm}$ & $139.5(38)$ & $144.2(27)$ & $142.3(49)$ & $0.449^{\#}$ \\
\hline Weight kg & $37.7(30)$ & $40.5(28)$ & $42.8(44)$ & $0.418^{\#}$ \\
\hline Boys & 16 (55.2) & $14(60.9)$ & 6 (66.7) & $0.808^{\text {fl }}$ \\
\hline Able to collect $100 \%$ of the target sample & 23 (79.3) & 15 (65.2) & 8 (88.9) & $0.300^{9}$ \\
\hline Time taken to collect sample $s$ & $721.7(257.8)$ & $765.8(240.2)$ & $752.8(294.8)$ & $0.265^{\#}$ \\
\hline
\end{tabular}


After sampling, all sorbent tubes were capped and placed in a fridge until dispatch to the laboratory, which was typically within $72 \mathrm{~h}$. To improve sample stability, the samples were dry purged on arrival at the University of Leicester for 2 min using nitrogen (CP grade; BOC, Leicester, UK) at a flow rate of $50 \mathrm{~mL} \cdot \mathrm{min}^{-1}$ and then stored in the fridge until ready for analysis.

\section{NASA Task Load Index (NASA-TLX)}

NASA-TLX is a widely used tool to assess perceived workload and effort and has been widely applied to healthcare assessments [26-28]. A visual analogue scale depicts six 7-point scales comprising: mental demand, physical demand, temporal demand, performance, effort and frustration, with a description to guide respondents in each section (figure 2). Increments of high, medium and low estimates for each point result in 21 gradations on the scales (low=1, high=21), with a midpoint threshold of 9.5 to indicate declining performance and increased perceived workload by participants [29]. For the purposes of this study, as with many research studies, we used "raw TLX" values, which is a shortened version of the original method. HART [30] compared the original version to the shortened version in 29 studies and concluded that using any of the versions over the other has no bearing on the overall results sensitivity. In this study the raw TLX was administered to assess the overall performance and feasibility of using the ReCIVA $^{\circ}$ mask for breath collection in patients with acute breathlessness. Adult patients were encouraged to complete the assessment immediately following breath collection. In the paediatric cohort we had trialled the use of this assessment of perceived task load but found that the children were not easily able to grasp the questions asked and the scales used, and felt that parents were not able to accurately comment on how easy their child perceived the task in terms of each domain of the NASA-TLX tool.

\section{RESULTS}

We include data for 65 adults recruited with community-acquired pneumonia $(n=15)$, heart failure $(n=14)$, acute asthma $(n=1)$, acute COPD $(n=21)$, and adult healthy controls $(n=14)$; and 61 children recruited

\begin{tabular}{|l|l|l|}
\hline Name & Task & Date \\
\hline
\end{tabular}

Mental demand

How mentally demanding was the task?

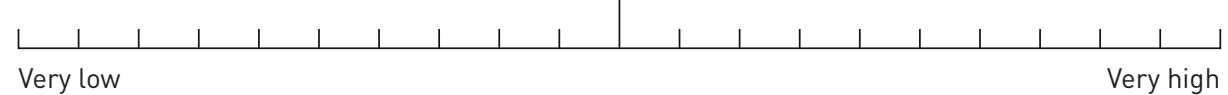

Physical demand

How physically demanding was the task?

$\begin{aligned} & \mid \\ & \text { Very low }\end{aligned} \mid$

Temporal demand

How hurried or rushed was the pace of the task?

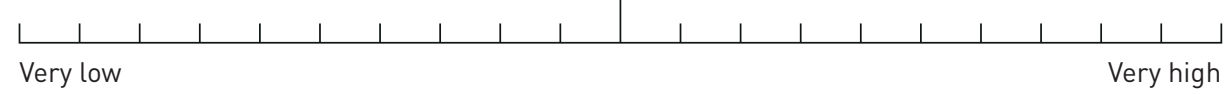

Performance

How successful were you in accomplishing what you were asked to do?

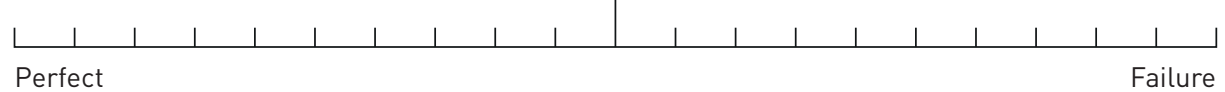

Effort

How hard did you have to work to accomplish your level of performance?

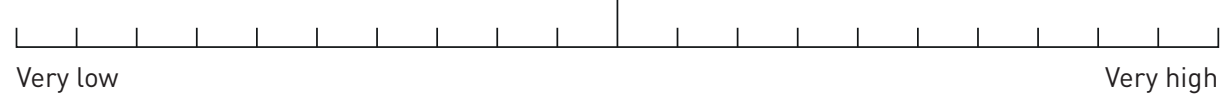

Frustration

How insecure, discouraged, irritated, stressed and annoyed were you?

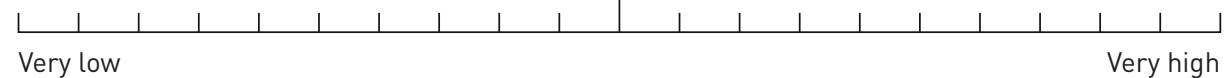

FIGURE 2 NASA Task Load Index scale. 
with stable, doctor-diagnosed chronic asthma $(\mathrm{n}=23)$, acute doctor-diagnosed asthma $(\mathrm{n}=29)$ and paediatric healthy controls $(n=9)$. Overall, we found that $98.4 \%$ of adults and $75.4 \%$ of children were able to provide $1 \mathrm{~L}$ of breath using the ReCIVA device. The demographic characteristics, proportion of participants able to collect $100 \%$ of the target breath sample, as well as the mean time taken, are shown in tables 1 and 2 for adults and paediatrics, respectively.

Amongst the children, we found no significant difference in the number able to provide a full sample between those with acute asthma, stable chronic asthma or controls, as shown in table 2. Likewise, there was no significant difference in the mean time taken to collect samples. Similarly, we found no significant difference between the number of adults with a diagnosis of acute asthma, acute COPD, acute heart failure, community-acquired pneumonia or controls in the ability to provide the full target sample of breath. We did, however, find that those with acute heart failure and those with pneumonia had a higher mean time taken to collect the sample.

In the adult population there was NASA index data on perceived task load available. Table 3 highlights the mean values for each category of the NASA measurement between the different diagnostic groups. We found that there was no significant difference in perceived task load in any domain amongst those with asthma/COPD, heart failure, community-acquired pneumonia or control participants.

\section{DISCUSSION}

In this feasibility study we report that it is possible to obtain breath samples using the ReCIVA ${ }^{\star}$ device from adults and children attending hospital with acute breathlessness to give analysable results. The procedure of breath collection was generally well tolerated by patients and acceptable to parents/guardians of children, which is demonstrated by the numbers of participants able to provide the full target breath samples. Doran et al. [31] described how they used the ReCIVA ${ }^{\infty}$ device in patients in their study assessing optimisation for breath sampling parameters including the fraction of breath sampled, the sample volume and the sample flow rate. The use of standardised breath collection devices allows for selection of breath sampled, i.e. from the lower airways.

In the present study, we found no significant difference across the different NASA-TLX domains between disease groups in adults and, importantly, between healthy volunteers and patients with acute breathlessness. However, it was apparent that the group diagnosed with community-acquired pneumonia did have higher scores within the domain of mental demand.

Further evaluation of NASA-TLX sub-scales showed that physical demand and effort scored relatively higher in comparison to the other domains. This finding can be explained by the fact that some participants chose to hold the ReCIVA ${ }^{\oplus}$ device, rather than use the head-strap, underestimating the effort it requires to hold the device for the duration of the procedure. It is worth noting that the reason this can be challenging is the way in which they need to hold the device to their face for the period of sampling rather than the device itself being heavy.

The emerging field of breathomics has already shown that breath profiling is a feasible concept with different methods of collecting breath samples being described. Collecting samples of breath via offline measurements for mass spectrometry analysis using Tedlar ${ }^{\circledR}$ bags is well established $[17,32,33]$. However, as described in a review by BEAUChamp et al. [19], there are several potential limitations of this methodology. Such issues include decay of certain groups of compounds, which affects the time for which samples can be stored, diffusion of compounds (such as acetonitrile) through the bag wall, and contamination of the bag wall with previous substances, which affects the limit of detection. They had

\section{TABLE 3 NASA Task Load Index measurements of perceived task load in adults}

\begin{tabular}{|c|c|c|c|c|c|}
\hline & Acute asthma or COPD & Acute heart failure & Pneumonia & Control & p-value $\pi$ \\
\hline Subjects $\mathbf{n}$ & 22 & 14 & 15 & 14 & \\
\hline Effort & $2.5(5)$ & $3.5(4)$ & $4(4)$ & $5(5)$ & 0.922 \\
\hline Frustration & $1.75(2)$ & $1.75(5)$ & $2.5(4)$ & $1.25(5)$ & 0.719 \\
\hline Mental demand & $2.5(4)$ & $3.5(3)$ & $2.5(4)$ & $5(4)$ & 0.774 \\
\hline Performance & $2.25(4)$ & $1.5(5)$ & $2(4)$ & $5(5)$ & 0.678 \\
\hline Physical demand & $5(6)$ & $3(4)$ & $5(3)$ & $5(5)$ & 0.418 \\
\hline Temporal demand & $2.25(4)$ & $2.75(4)$ & $2.5(4)$ & 5 (5) & 0.935 \\
\hline
\end{tabular}


identified that the groups of compounds which showed significant decreases in signals detected within $10 \mathrm{~h}$ of storage included hexanals, acetonitrile and water vapour. They demonstrated a concentration-dependent decay rate for many groups of compounds. This means that time-consuming consideration of factors such as cleaning procedures, sampling procedures and storage procedures are needed when using Tedlar ${ }^{\circledR}$ bags. The ReCIVA $^{\oplus}$ handheld portable device allows samples of breath to be collected directly onto sorbent tubes with pre-concentration of VOCs. It has been described that when samples collected onto sorbent tubes are stored in a refrigerator, if analysed within 2 weeks there is minimal gain or loss of VOC concentration [34]. However, consumables used for the ReCIVA ${ }^{\star}$ breath sampling, such as the disposable masks, must be vacuum- and temperature-conditioned prior to use to reduce siloxane-based contamination. This source of contamination could affect both instrumentation performance and consequently an imminent need for instrument maintenance. This may also complicate data processing and statistical modelling and consequently delay biomarker discovery. The results of our study demonstrate the acceptability of using this handheld device to collect breath samples and the NASA-TLX measurements of perceived task load emphasise how little effort and demand is required to collect these samples in acutely unwell patients.

Being able to apply this technique of collecting breath samples in such a way that allows minimisation of contamination and decay of compounds would be a huge clinical advance in assessing breathlessness and cardiorespiratory disease in adults and children. For example, asthma is the most common chronic condition in childhood [24], but investigating airway inflammation in this young age group is both ethically and technically challenging. Noninvasive methods of investigating airway inflammation could allow for potential profiling of children with asthma, which could aid management of this common condition. Exhaled breath VOC profiling has already been performed in children with a clinical asthma diagnosis [25] and furthermore in preschool children with wheeze [26]. In both of these studies, breath samples were collected by filling Tedlar bags, where the samples then passed from the bag through sorbent tubes. These studies identified differences in the compounds detected between those with asthma/ wheeze and healthy controls. However, as aforementioned, the use of Tedlar bags for breath collection is not without limitation. The ReCIVA ${ }^{\oplus}$ device has been successfully used to collect breath samples from children within this study, negating the need for collection bags. We found that fewer children were able to collect a fully analysable sample compared to the adult population (75\% versus $98 \%)$. It is not surprising that young children may find attending to this task difficult and distraction techniques or a great deal of encouragement is needed in this younger group. We found no significant differences between children able and unable to provide an analysable sample in terms of age or category (acute or chronic asthma or healthy volunteer) (data not shown). It is unfortunate that we were not able to apply the NASA-TLX scoring to the paediatric population as this may have given an indication to a particular area that was perceived as more challenging in this young group. As far as the authors are aware, there is not a NASA-TLX scale that has yet been adapted for use in a paediatric population. We accept that a limitation of this study is the absence of data in the form of a questionnaire administered to parents/carers or young people, which may have been able to provide some insight into specific difficulties of breath sampling using this device, however this was not within our original Research Ethics Committee application.

In summary, we have demonstrated in this single-centre feasibility study that it is possible to collect samples of breath from both adults and children with acute breathlessness as well as chronic, stable asthma in children and healthy adult and child volunteers using the ReCIVA ${ }^{\circ}$ device. There were no significant differences in the ability of patients to give the full target sample of breath in terms of their underlying diagnosis or in their perceived effort required. The next stage of development is to establish a workflow and method to analyse these breath samples and create breath matrices to ascertain differences in eVOCs in those with different cardiorespiratory conditions and healthy controls. Further to this, recruitment of larger numbers of adults and children into a multicentre study is needed to obtain a greater number of breath samples to further expand on this advancing field of breathomics.

Acknowledgements: The authors would like to acknowledge the invaluable efforts of the research nurses responsible for the in-clinic sample collection as well as the input from the wider EMBER consortium (a list of members can be found at https://ember.le.ac.uk/web).

Support statement: Research funding was provided by the MRC and EPSRC Stratified Medicine Grant for Molecular Pathology Nodes (grant number MR/N005880/1). The research was supported by the National Institute for Health Research (NIHR) Leicester Biomedical Research Centre - Respiratory and Cardiovascular Themes, NIHR, Leicester Clinical Research Facility, the British Lung Foundation and the Midlands Asthma and Allergy Research Association, to whom we are extremely grateful. The views expressed are those of the author(s) and not necessarily those of the National Health Service and NIHR or the Department of Health. Funding information for this article has been deposited with the Crossref Funder Registry.

Conflict of interest: K.A. Holden reports grants from the Medical Research Council and the Engineering and Physical Sciences Research Council EMBER Node Consortium, the British Lung Foundation, and the Midlands Asthma and Allergy Research Association, during the conduct of the study. W. Ibrahim reports grants from the Medical Research 
Council and the Engineering and Physical Sciences Research Council EMBER Node Consortium, the British Lung Foundation, and the Midlands Asthma and Allergy Research Association, during the conduct of the study. D. Salman reports grants from the Medical Research Council and the Engineering and Physical Sciences Research Council EMBER Node Consortium, the British Lung Foundation, and the Midlands Asthma and Allergy Research Association, during the conduct of the study. R. Cordell reports grants from the Medical Research Council and the Engineering and Physical Sciences Research Council EMBER Node Consortium, the British Lung Foundation, and the Midlands Asthma and Allergy Research Association, during the conduct of the study. T. McNally reports grants from the Medical Research Council and the Engineering and Physical Sciences Research Council EMBER Node Consortium, the British Lung Foundation, and the Midlands Asthma and Allergy Research Association, during the conduct of the study. B. Patel reports grants from the Medical Research Council and the Engineering and Physical Sciences Research Council EMBER Node Consortium, the British Lung Foundation, and the Midlands Asthma and Allergy Research Association, during the conduct of the study. R. Phillips reports grants from the Medical Research Council and the Engineering and Physical Sciences Research Council EMBER Node Consortium, the British Lung Foundation, and the Midlands Asthma and Allergy Research Association, during the conduct of the study. C. Beardsmore reports grants from the Medical Research Council and the Engineering and Physical Sciences Research Council EMBER Node Consortium, the British Lung Foundation, and the Midlands Asthma and Allergy Research Association, during the conduct of the study. M. Wilde reports grants from the Medical Research Council and the Engineering and Physical Sciences Research Council EMBER Node Consortium, the British Lung Foundation, and the Midlands Asthma and Allergy Research Association, during the conduct of the study. L. Bryant reports grants from the Medical Research Council and the Engineering and Physical Sciences Research Council EMBER Node Consortium, the British Lung Foundation, and the Midlands Asthma and Allergy Research Association, during the conduct of the study. A. Singapuri reports grants from the Medical Research Council and the Engineering and Physical Sciences Research Council EMBER Node Consortium, the British Lung Foundation, and the Midlands Asthma and Allergy Research Association, during the conduct of the study. P. Monks reports grants from the Medical Research Council and the Engineering and Physical Sciences Research Council EMBER Node Consortium, the British Lung Foundation, and the Midlands Asthma and Allergy Research Association, during the conduct of the study. C. Brightling reports grants from the Medical Research Council and the Engineering and Physical Sciences Research Council EMBER Node Consortium, the British Lung Foundation, and the Midlands Asthma and Allergy Research Association, during the conduct of the study; grants and personal fees from AstraZeneca, GlaxoSmithKline, Novartis, Merck, Gossamer, 4DPharma, Boehringer Ingelheim and Mologic, personal fees from TEVA, grants from Genentech/Roche, and personal fees from Sanofi, outside the submitted work. N. Greening reports grants from the Medical Research Council and the Engineering and Physical Sciences Research Council EMBER Node Consortium, the British Lung Foundation, and the Midlands Asthma and Allergy Research Association, during the conduct of the study; research funding and lecture honoraria from GSK, and lecture honoraria and conference travel from AstraZeneca, Boehringer Ingelheim and Chiesi, outside the submitted work. P. Thomas reports grants from the Medical Research Council and the Engineering and Physical Sciences Research Council EMBER Node Consortium, the British Lung Foundation, and the Midlands Asthma and Allergy Research Association, during the conduct of the study; and grants from TOXI-triage (this project has received funding from the European Union's Horizon 2020 research and innovation programme under grant agreement number 653409), outside the submitted work. S. Siddiqui reports grants from the Medical Research Council and the Engineering and Physical Sciences Research Council EMBER Node Consortium, the British Lung Foundation, and the Midlands Asthma and Allergy Research Association, during the conduct of the study; grants from TOXI-triage (this project has received funding from the European Union's Horizon 2020 research and innovation programme under grant agreement number 653409), personal fees from Owlstone Medical Ltd and Mundipharma, and advisory board fees from GlaxoSmithKline, AstraZeneca, Novartis, Chiesi and Roche, outside the submitted work. E.A. Gaillard reports grants from the Medical Research Council and the Engineering and Physical Sciences Research Council EMBER Node Consortium, the British Lung Foundation, and the Midlands Asthma and Allergy Research Association, during the conduct of the study; consultancy fees paid to the University of Leicester from Boehringer Ingelheim and Anaxsys, investigator-led research grants from Circassia, Gilead and Chiesi Ltd, and a research collaboration grant from Medimmune, outside the submitted work.

\section{References}

1 Punekar YS, Mullerova H, Small M, et al. Prevalence and burden of dyspnoea among patients with chronic obstructive pulmonary disease in five European countries. Pulm Ther 2016; 2: 59-72.

2 Rabe KF. Improving dyspnea in chronic obstructive pulmonary disease: optimal treatment strategies. Proc Am Thorac Soc 2006; 3: 270-275.

3 Global strategy for the diagnosis, management, and prevention of chronic obstructive pulmonary disease 2020 . https://goldcopd.org/wp-content/uploads/2019/12/GOLD-2020-FINAL-ver1.2-03Dec19_WMV.pdf

4 Parshall MB, Schwartzstein RM, Adams L, et al. An official American Thoracic Society statement: Update on the mechanisms, assessment, and management of dyspnea. Am J Respir Crit Care Med 2012; 185: 435-452.

5 Murdoch JR, Lloyd CM. Chronic inflammation and asthma. Mutat Res 2010; 690: 24-39.

6 Calenic B, Miricescu D, Greabu M, et al. Oxidative stress and volatile organic compounds: interplay in pulmonary, cardio-vascular, digestive tract systems and cancer. Open Chem 2015; 13: 636-655.

7 Besa V, Darwiche K, Teschler H, et al. Volatile organic compounds (VOCs) in COPD patients with exacerbation. Eur Respir J 2011; 38: Suppl. 55, 4788.

8 Esteban JJ, Lucas MA, Aranda BC, et al. Volatile organic compounds (VOC) in exhaled breath in patients with lung cancer, using the analytical technique thermal desorber-gase chromatography-spectrometer mases. Eur Respir J 2012; 40: Suppl. 56, 4204.

9 Ibrahim B, Basanta M, Cadden P, et al. Non-invasive phenotyping using exhaled volatile organic compounds in asthma. Thorax 2011; 66: 804-809.

10 Samara MA, Paschke KM, Tang WW, et al. Single breath exhaled gas analysis by selected ion-flow tube mass-spectrometry (SIFT-MS) in patients with acute decompensated heart failure. J Card Fail 2011; 17: S4.

11 Gahleitner F, Guallar-Hoyas C, Beardsmore CS, et al. Metabolomics pilot study to identify volatile organic compound markers of childhood asthma in exhaled breath. Bioanalysis 2013; 5: 2239-2247.

12 Ibrahim W, Wilde M, Cordell R, et al. Assessment of breath volatile organic compounds in acute cardiorespiratory breathlessness: a protocol describing a prospective real-world observational study. BMJ Open 2019; 9: e025486. 
13 Kitchen S, Edge A, Smith R, et al. Breathe free: open source development of a breath sampler by a consortium of breath researchers. Eur Respir J 2015; 46: Suppl. 59, PA3987.

14 Cristescu SM, Gietema HA, Blanchet L, et al. Screening for emphysema via exhaled volatile organic compounds. J Breath Res 2011; 5: 046009.

15 Dragonieri S, Schot R, Mertens BJ, et al. An electronic nose in the discrimination of patients with asthma and controls. J Allergy Clin Immunol 2007; 120: 856-862.

16 Montuschi P, Santonico M, Mondino C, et al. Diagnostic performance of an electronic nose, fractional exhaled nitric oxide, and lung function testing in asthma. Chest 2010; 137: 790-796.

17 Shafiek H, Fiorentino F, Merino JL, et al. Using the electronic nose to identify airway infection during COPD exacerbations. PLoS One 2015; 10: e0135199.

18 Steeghs MM, Cristescu SM, Harren FJ. The suitability of Tedlar bags for breath sampling in medical diagnostic research. Physiol Meas 2007; 28: 73-84.

19 Beauchamp J, Herbig J, Gutmann R, et al. On the use of Tedlar(R) bags for breath-gas sampling and analysis. J Breath Res 2008; 2: 046001.

20 Kwak J, Fan M, Harshman SW, et al. Evaluation of Bio-VOC sampler for analysis of volatile organic compounds in exhaled breath. Metabolites 2014; 4: 879-888.

21 Phillips CO, Syed Y, Mac Parthaláin N, et al. Machine learning methods on exhaled volatile organic compounds for distinguishing COPD patients from healthy controls. J Breath Res 2012; 6: 036003

22 Scarlata S, Finamore P, Santangelo S, et al. Cluster analysis on breath print of newly diagnosed COPD patients: effects of therapy. J Breath Res 2018; 12: 036022.

23 Exhaled Breath Metabolomic Biomarkers in the Acutely Breathless Patient (EMBER). 2019. https:/clinicaltrials. gov/ct2/show/NCT03672994?term=Wadah+ibrahim\&rank=1

24 Wilde MJ, Cordell RL, Salman D, et al. Breath analysis by two-dimensional gas chromatography with dual flame ionisation and mass spectrometric detection - method optimisation and integration within a large-scale clinical study. J Chromatogr A 2019; 1594: 160-172.

25 Zhao B, Wilde M, Cordell C, et al. LabPipe: an extensible informatics platform to streamline management of metabolomics data and metadata. 2019 arXiv:1910.13246.

26 Colligan L, Potts HW, Finn CT, et al. Cognitive workload changes for nurses transitioning from a legacy system with paper documentation to a commercial electronic health record. Int J Med Inform 2015; 84: 469-476.

27 Young G, Zavelina L, Hooper V. Assessment of workload using NASA Task Load Index in perianesthesia nursing. J Perianesth Nurs 2008; 23: 102-110.

28 Lowndes BR, Forsyth KL, Blocker RC, et al. NASA-TLX assessment of surgeon workload variation across specialties. Ann Surg 2018; 271(4): 686-692.

29 Hart SG, Staveland LE. Development of NASA-TLX (Task Load Index): results of empirical and theoretical research. In: PA Hancock, N Meshkati, eds. Human Mental Workload. Amsterdam, North Holland Press, 1988.

30 Hart SG. Nasa-Task Load Index (NASA-TLX); 20 years later. Proc Hum Factors Ergon Soc Annu Meet 2006; 50: 904-908.

31 Doran SL, Romano A, Hanna GB. Optimisation of sampling parameters for standardised exhaled breath sampling. J Breath Res 2017; 12: 016007.

32 Van Berkel JJ, Dallinga JW, Möller GM, et al. A profile of volatile organic compounds in breath discriminates COPD patients from controls. Respir Med 2010; 104: 557-563.

33 Cazzola M, Segreti A, Capuano R, et al. Analysis of exhaled breath fingerprints and volatile organic compounds in COPD. COPD Res Pract 2015; $1: 7$.

34 Harshman SW, Mani N, Geier BA, et al. Storage stability of exhaled breath on Tenax TA. J Breath Res 2016; 10: 046008 . 